\title{
DERIVED RELATIONAL NETWORKS AND CONTROL BY NOVEL INSTRUCTIONS: A POSSIBLE MODEL OF GENERATIVE VERBAL RESPONDING
}

\section{DENIS O'HORA, DERMOT BARNES-HOLMES and BRYAN ROCHE National University of Ireland, Maynooth}

\author{
PAUL SMEETS \\ Leiden University, The Netherlands
}

\begin{abstract}
Relational Frame Theory proposes that control by novel instructions may be understood as control by networks of Same and Before or After relations. The current paper reports two experiments in which such control was demonstrated. In Experiment 1, undergraduate students were first trained to respond in accordance with Before and After relations and then trained to respond in accordance with Same and Different relations. Subjects were then presented with a number of 'instructions' in the form of networks of Same, Different, Before, and After relations in the absence of reinforcement. Of the 3 students, 2 demonstrated the required performance within two exposures to the final phase of the experiment. In Experiment 2, 5 of 8 additional subjects who demonstrated instructional control also did so in the presence of 24 novel stimulus sets without further training. The implications of these novel and generative performances for the analysis of instructional control and human language more generally are considered.
\end{abstract}

Skinner (1969) proposed that instructional control occurred because of the contingency-specifying properties of instructions. The foregoing definition provided a starting point for the experimental analysis of the complex effects of instructions on human behavior that had been demonstrated at that time by researchers such as Ayllon and Azrin (1964), and Kaufman, Baron, and Kopp (1966). To date, the dominant focus of the experimental analysis of instructional control has been on the characteristics of instructed responding once established (see Hayes, Zettle, \& Rosenfarb,

Requests for reprints should be addressed to Dermot Barnes-Holmes, National University of Ireland, Maynooth, Co. Kildare, Ireland. These data were submitted as part of Denis O'Hora's doctoral work, which was supported by a Government of Ireland Scholarship in the Humanities and Social Sciences and a Research Studentship from National University of Ireland, Maynooth. Denis O'Hora expresses his heartfelt thanks to his collaborators and to everyone in the Department of Psychology in NUI Maynooth. He is now at the University of Ulster, Coleraine, Northern Ireland. 
1989, for a review). Consequently, the vast majority of studies in the empirical literature have examined instructions as stimuli with certain properties (e.g., specifying contingencies) that are explained in terms of the subject's preexperimental history in the verbal community. One might argue, however, that a more complete understanding of instructional control includes focusing on the behavioral processes involved in establishing, $a b$ initio, this type of control under laboratory conditions (O'Hora \& BarnesHolmes, 2001; O'Hora, Barnes-Holmes, \& Roche, 2001).

In fact, in one recent study, Okouchi (1999) did attempt to establish instructional control by novel stimuli based on a tightly controlled experimental history. Based on earlier conceptual work by Skinner (1969), Okouchi (1999) demonstrated instructional control in opposition to the literal meaning of the words by providing differential reinforcement histories. Okouchi suggested that this was evidence that a history of differential reinforcement may explain control by certain instructions. However, in discussing the performance of a control group in this study, he suggested that instructional control observed in that group may not have been discriminative, but rather might be attributed to a transfer of function within an equivalence class that included the presented instruction (p. 213). One study that explored the role of derived transfer of function in establishing instructional control was conducted by L. J. Hayes, Thompson, and S. C. Hayes (1989).

In the foregoing study (Experiment 1), L. J. Hayes et al. trained two equivalence classes. First, they trained a 'timing' equivalence class, which included musical notes (e.g., ad), the names of those notes (e.g., quarter note, half note) and tones of different duration. Second, they trained a 'placement' equivalence class, which included positions on a musical staff (e.g., $\overline{\overline{\#}}$ ), the names of those positions (e.g., A, B, C\#), tones of differing pitch, and the corresponding keys on a piano keyboard. Three groups of subjects were used. One group was exposed to training on the 'timing' class alone, one to training on the 'placement' class alone, and a final group to training on both the 'timing' and 'placement' classes. Following training, the musical notes and the staff were combined as compound stimuli in an unreinforced test session in which subjects were asked to play a number of notes on the keyboard, each with a particular length and a particular pitch. Subjects exposed to 'timing' training alone played the notes at the wrong pitch, but for the right duration, subjects exposed to 'placement' training alone played notes at the right pitch, but for the wrong duration, and subjects exposed to both 'timing' and 'placement' training played notes at the right pitch and for the right duration.

L. J. Hayes et al. produced sequences of behaviors based on derived transfer (i.e., without direct training), and, as such, provided an experimental analog of the types of control usually attributed to novel instructions. One crucial consideration, however, concerns the fact that $\mathrm{L}$. J. Hayes et al. depended on the subjects' preexperimental history of reading in order to establish the correct sequence of derived responses. That is, in order for the visually presented musical notes to occasion the 
correct sequence of 'timing' and 'placement' responses, it was necessary for subjects to read from left to right. Ideally, however, a robust experimental analog of instructional control should allow for control over the behavioral sequence itself. In the natural environment, for example, instructions may sometimes be phrased in a particular way to control a specific behavioral sequence (e.g., "You must wash the dishes before you watch TV"), but they may then be rephrased in order to reverse that sequence (e.g., "You must wash the dishes after you watch TV).

One recent conceptual approach to instructional control addresses the foregoing reversibility of such control in terms of responding in accordance with derived (or untrained) stimulus relations other than equivalence. Specifically, S. C. Hayes and L. J. Hayes (1989) provided an interpretation of the instruction "When the bell rings, then go to the oven and get the cake" suggested by Relational Frame Theory (RFT). Hayes and Hayes explained the control established by this instruction in terms of the participation of the words in equivalence relations with actual events (i.e., the word "bell" with actual bells, the word "oven" with actual ovens), and the relational control provided by the contextual cues for 'before' and 'after' relations (i.e., "when," "then," and "and" established the sequence; bell BEFORE oven BEFORE cake). In this way, the observation of the sequence specified by the instruction may be explained in terms of responding in accordance with the derived relations (i.e., equivalence and Before/After) occasioned by the instruction. Thus, the reversibility of instructional control described previously (e.g., "wash the dishes before you watch TV" and "wash the dishes after you watch TV") may be explained in terms of the presentation of the contextual cues 'before' and 'after.' This conceptual approach, therefore, includes the types of performances demonstrated in the L. J. Hayes et al. (1989) study, but also suggests that the instructional control that we usually observe is often more complex and requires responding in accordance with multiple stimulus relations or relational networks.

The experiments described in the current article constitute the first empirical attempts to demonstrate instructional control as responding in accordance with a network of derived stimulus relations. Specifically, the current experiments aimed to provide an empirical model of the control suggested by Hayes and Hayes in the instruction "When the bell rings, take the cake from the oven." In doing so, it was necessary to establish responding in accordance with the following relations: Same, Different, Before, and After.

Responding in accordance with Same and Different relations was demonstrated in a study by Steele and Hayes (1991). In that study, subjects were trained to respond in accordance with Same, Different, and Opposite relations in the presence of arbitrary contextual cues using a modified match to sample procedure. Specifically, Steele and Hayes trained subjects to choose Same stimuli (e.g., a large line with a large line) in the presence of one contextual cue, Opposite stimuli (e.g., a large line with a small line) in the presence of a second contextual cue, and 
Different stimuli (e.g., a circle with a cross) in the presence of a third contextual cue. These subjects were then trained in an extensive network of conditional discriminations, and each discrimination was made in the presence of one of the three contextual cues. The arbitrary contextual cues then reliably controlled subjects' performances on unreinforced tests. Several further articles have since reported similar outcomes (Dymond \& Barnes, 1995; O'Hora, Roche, Barnes-Holmes, \& Smeets, 2002; Roche \& Barnes, 1996, 1997). The current study employed a novel procedure, the Relational Evaluation Procedure (REP; Cullinan, BarnesHolmes, \& Smeets, 1998, 2000, 2001; S. C. Hayes \& Barnes, 1997; Barnes-Holmes, Hayes, Dymond, \& O'Hora, 2001) in order to establish contextual control over Before and After relational responding.

In Experiment 1, subjects were first exposed to relational pretraining and testing for Before and After relational responding using an REP procedure, and they were then tested on a number of novel stimulus sets. Subjects were then trained to respond in accordance with Same and Different. In the final phase of Experiment 1, subjects were exposed to a test for instructional control consisting of a number of novel complex probes that each specified a particular four-key response sequence in accordance with derived Same, Different, Before, and After relations. Experiment 2 investigated the generativity of this relational responding by exposing subjects to a further stage in which probes employed stimuli from 24 novel stimulus sets.

\section{Experiment 1}

\section{Method}

\section{Subjects}

Three undergraduates, 2 male and 1 female, attending the National University of Ireland, Maynooth volunteered to take part in the study. Subjects were aged between 19 and 23 years and were recruited through personal contacts. None of the subjects had previously participated in psychological experiments.

\section{Apparatus}

Subjects were seated in a small experimental room (6' $\left.X 6^{\prime}\right)$ before an Apple Imac ${ }^{\circledR}$ computer with a 14" display on which all training and testing tasks were presented. The letters $\mathrm{Z}, \mathrm{C}, \mathrm{B}$, and $\mathrm{M}$ on the keyboard were covered by different colored squares of masking tape (green, red, blue, and yellow, respectively). Presentation of stimuli and recording of responses were controlled by the experiment generating software application PsyScope (Cohen, MacWhinney, Flatt, \& Provost, 1993).

Four stimuli, each consisting of a string of three characters (i.e., $\% \% \%, ! ! !,()(), \ldots::)$ were used as contextual stimuli and assigned the roles of Same, Different, Before, and After. Geometric shapes were employed as stimuli during relational pretraining and testing. Eight nonsense 
syllables (LIB, DAX, MIM, VEK, CUG, GAN, JOM, MUB) and four colored squares (green, red, blue, and yellow) served as stimuli during the test for instructional control. In the interests of clarity, the nonsense syllables will be referred to using the alpha-numerics $\mathrm{B} 1, \mathrm{~B} 2, \mathrm{~B} 3, \mathrm{~B} 4, \mathrm{C} 1, \mathrm{C} 2, \mathrm{C} 3$, and C4 (subjects were not exposed to these labels).

\section{General Procedure}

\section{Experimental Overview}

In order to analyze instructional control in accordance with the current model in the laboratory, it was necessary to establish responding in accordance with the following relations: Same, Different, Before, and After. Subjects were first trained to respond according to Before and After relations using an REP procedure (see Figure 1). When subjects satisfied the mastery criterion on a test for Before and After relational responding, they were exposed to pretraining for Same and Different relational responding. Responding in accordance with Same and Different was achieved by exposing subjects to a modified match-to-sample procedure (see Figure 2). Subjects were then exposed to a test for Same and Different relational responding.

The purpose of the pretraining and testing tasks was to establish contextual control of the Same, Different, Before, and After relational responses in four arbitrary contextual cues (i.e., \%\%\%, !!!, ()(), ::::). In the following text, the words SAME, DIFFERENT, BEFORE, and AFTER will be in used in all capitals to denote the contextual cue for each particular function. Once, subjects satisfied the mastery criterion in these four phases, they were exposed to the test for instructional control, in which subjects were presented with a number of networks of Same and Before or After relations (see Figure 3).

All trials were presented on the computer monitor. Feedback followed responses on all training trials, which was followed in turn by an intertrial interval (i.e., the screen remained blank for $2.5 \mathrm{~s}$ ). Following a correct response, the screen cleared, and the word "Correct" appeared accompanied by a short beep from the computer. Following an incorrect response, the word "Wrong" appeared accompanied by a short lowpitched tone.

Nonarbitrary Pretraining and Testing for Before and After Relational Responding

The following instructions were presented to subjects before pretraining and testing for Before and After relational responding.

In a moment two sets of images will appear on the screen. Next, two further images will appear at the top of the screen. Look at these two images and then choose one of the sets of images that appeared at the start.

If you wish to choose the set of images on the left, choose the colored button furthest to the left. If you wish to choose the set of 
images on the right then you should press the colored button furthest to the right.

Hit any key when you are ready to begin.

In order to train responding in accordance with before and after relations, two shapes were presented in a particular order (e.g., circle ... square) and subjects were required to choose one of two sets of stimuli which included these stimuli and relational cues (e.g., circle BEFORE square or square AFTER circle; see Figure 1). During each pretraining trial and test probe, two sets of stimuli were first presented at the bottom left and right corners of the screen. Reading from bottom to top, the sets of stimuli consisted of two arbitrary shapes (e.g., a square and a circle) with an arbitrary contextual cue for BEFORE or AFTER (e.g., ()()) presented between them (e.g., 'circle ()() square' /'circle ()() square'). Both sets of stimuli were presented in a temporal sequence from bottom to top. The first arbitrary shapes in both sets were presented simultaneously at opposite sides of the screen followed by the contextual cues just above them and

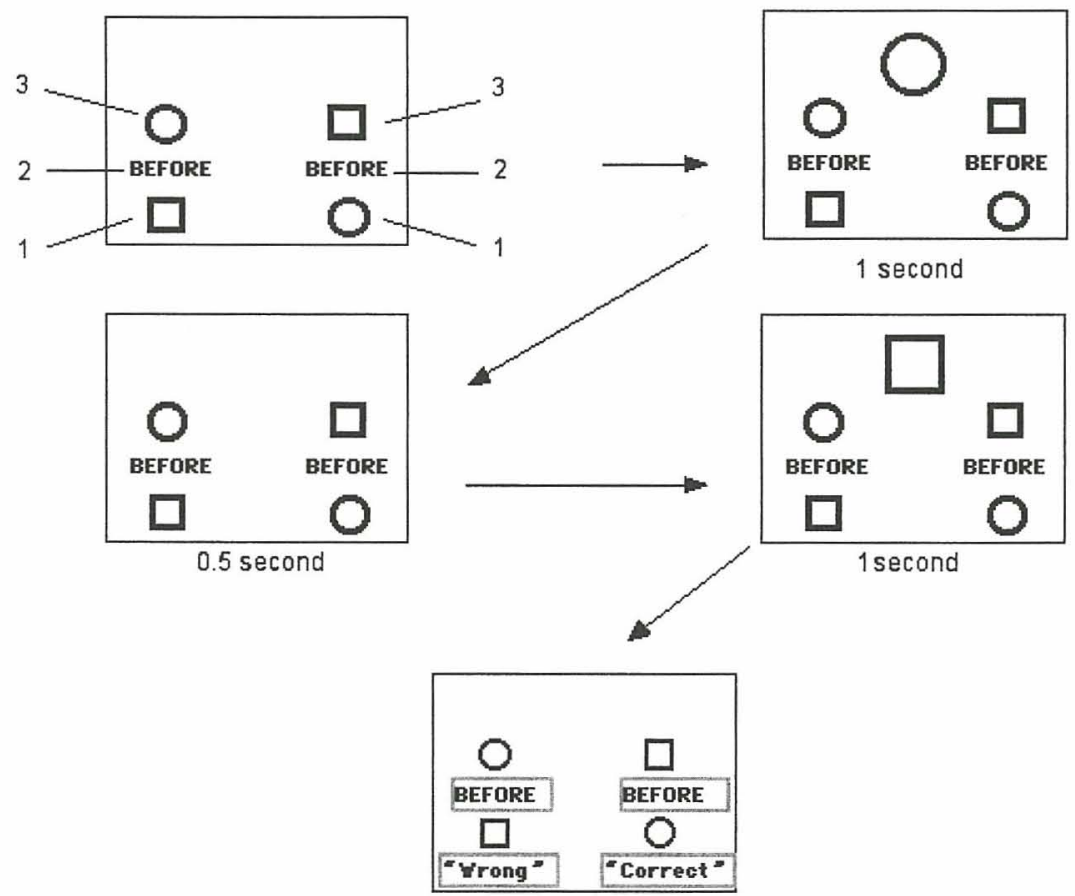

Figure 1. Flow chart outlining a representative task from pretraining for Before and After relational responding. Note that the elements on the initial screen appeared in the order indicated (i.e., the bottom elements were presented first, followed $0.5 \mathrm{~s}$ later by the middle elements, and then $0.5 \mathrm{~s}$ later by the top elements. The words Before and After were not presented to subjects, but are used here to indicate the functions established in arbitrary contextual cues. Test probes were identical in form but novel arbitrary shapes were employed and no reinforcement was provided. 
finally the second arbitrary shapes. After an interval of $2.5 \mathrm{~s}$, the first shape (e.g., a circle) was presented in the middle of the screen above the sets of stimuli for $1 \mathrm{~s}$, then after $0.5 \mathrm{~s}$, the second shape (e.g., a square) that was included in both sets was also presented for $1 \mathrm{~s}$.

Reinforcement was delivered for choosing one of the two sets of stimuli contingent upon the order in which the two latter shapes (e.g., circle ... square) were presented. For example, if a circle was presented in the center of the screen, followed by a square, then choosing 'circle ()() square' was reinforced. After a number of such trials, the arbitrary contextual cue $(()())$ acquired the function of Before. Similarly, if a circle was presented in the center of the screen, followed by a square, then choosing 'square ::.:: circle' was reinforced. In this way, the second arbitrary contextual cue ( :::: ) acquired the function of After.

Arbitrary shapes were used as stimuli during pretraining trials for Before and After relations. For each pair of shapes (e.g., circle and square), there were four 'choice situations' presented. That is, when a circle was presented before a square in the middle of the screen, there were four possible choices that might be presented at the bottom of the screen (in each case, the reinforced choice is in italics):

'circle BEFORE square' or 'square BEFORE circle,'

'circle AFTER square' or 'square AFTER circle,'

'circle BEFORE square' or 'circle AFTER square,'

'square BEFORE circle' or 'square AFTER circle.'

Each block of 16 trials included equal numbers of each 'choice situation; equal numbers of trials with each arbitrary shape as the first presented and equal number of trials in which the left or right option was correct. The mastery criterion for pretraining was set at 14/16 on the last block of trials. Following pretraining, subjects were exposed to two blocks of test probes that utilized two novel stimulus pairs and the mastery criterion was 30/32 probes correct. If subjects continued to fail to demonstrate the required performance after exposure to 12 blocks of 16 trials, they were excused from the experiment. No subjects failed at this stage.

When subjects satisfied the mastery criterion on the test for Before and After relational responding, they were exposed to pretraining and testing for Same and Different relations. Subjects who did not satisfy the mastery criterion on this test were reexposed to pretraining for Before and After relations.

\section{Nonarbitrary Pretraining and Testing for Same and Different Relations}

The following instructions were presented in the middle of the computer screen:

In a moment some images will appear on this screen. Your task is to look at the image at the bottom of the screen, then look at the images in the middle of the screen, and at the top of the screen. On the basis of these images, choose one of the images at the bottom of the screen by pressing one of the colored buttons in front of you. 
If you want to choose the image on the left, choose the colored button furthest to the left. If you want to choose the image on the right, choose the colored button furthest to the right.

Hit any key when you are ready to begin

On any task, the comparison stimuli appeared in the bottom left and right corners of the screen. The screen position of the comparisons (i.e., left or right) was counterbalanced across trials. After a 1-s delay the sample stimulus appeared in the middle of the screen. Following a further 1-s delay, the contextual cue (represented in Figure 2 as SAME or DIFFERENT) appeared in the center top third of the screen. The contextual cue, sample, and comparisons remained on the screen until a response was recorded. In the presence of one contextual cue, choosing the comparison stimulus that was the same as the sample stimulus was reinforced. In the presence of another contextual cue, choosing the comparison that was different from the sample stimulus was reinforced. In this way, the arbitrary contextual cues came to control responding according to Same or Different relations between sample and comparison stimuli.

Arbitrary shapes were used as stimuli during pretraining trials for

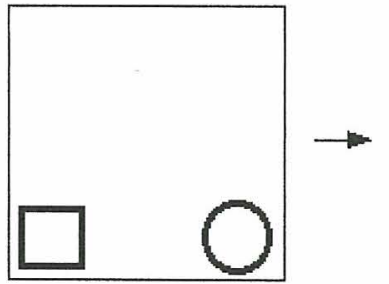

0.5 sec

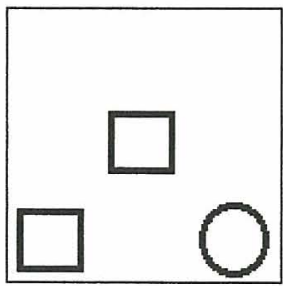

$0.5 \mathrm{sec}$

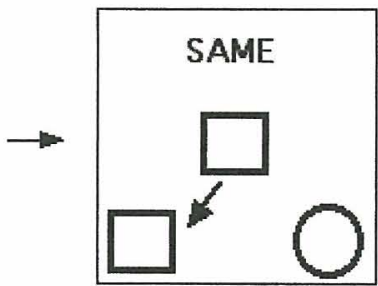

$0.5 \mathrm{sec}$

Figure 2. A diagrammatic representation of a task from the nonarbitrary relational pretraining for Same and Different relations. Unlike the tasks described in stimuli appeared on the screen sequentially from bottom to top (i.e., comparison stimuli first, then sample, then contextual cue). Subjects were reinforced for choosing the same comparison stimulus as the sample stimulus in the presence of the SAME contextual cue and for choosing the comparison that was different from the sample in the presence of the DIFFERENT contextual cue.

Same and Different relations. During any particular trial, one shape (e.g., a square) was presented as sample, and two shapes were presented as comparison stimuli (e.g., a square and a circle). In order to establish the relational responses of Same and Different, one of the two comparison stimuli was the same shape as the sample stimulus. The arbitrary shapes were grouped in sets of two and trials were counterbalanced such that each arbitrary shape within a set was presented as a sample. Subjects were exposed to blocks of eight pretraining trials that each consisted of two stimulus sets presented twice. Initially subjects were exposed to two blocks of eight trials, and subsequently subjects were exposed to single blocks of eight training trials. The mastery criterion for pretraining for Same and Different relations was seven correct responses out of eight on 
the last block of pretraining trials presented. If subjects continued to fail to demonstrate the required performance after exposure to 12 blocks of eight trials, they were excused from the experiment.

When subjects achieved the mastery criterion, they were exposed to a testing session that consisted of two blocks of eight trials, during which no reinforcement was provided and the samples and comparisons were novel stimuli. If subjects satisfied the mastery criterion on the test for Same and Different relational responding (15/16 correct), they were exposed to the Test for Instructional Control. If subjects failed to achieve this level of responding, they were reexposed to pretraining for Same and Different relations.

\title{
Test for Instructional Control
}

Given the above experimental history of reinforcement, four contextual cues had been established for responding in accordance with Same, Different, Before, and After relations. In the next phase of the experiment, subjects were presented with 36 'instruction' probes in the form of networks of Same, Different, Before, and After relations without reinforcement (see Figure 3). The following instructions were presented to subjects before they were exposed to the Test for Instructional Control:

\begin{abstract}
In a moment a series of images will appear at the bottom of this screen. A second series of images will then appear above those images. You must press the colored keys on the keyboard in a particular sequence based on the images on the computer screen. When you are finished pressing the colored keys, you must press the RETURN key to proceed.
\end{abstract}

Hit any key when you are ready to begin.

Instruction probes consisted of nonsense syllables, contextual cues that had been established in pretraining and colored squares that corresponded to colored response keys on the keyboard. By presenting these stimuli in certain patterns, it was now possible to test for networks of relational responding. In this section, nonsense syllables are denoted by the alphanumerics $\mathrm{B} 1$ to $\mathrm{B} 4$ and $\mathrm{C} 1$ to $\mathrm{C} 4$, the colored squares are denoted by the alpha-numerics A1 to A4 and, as previously, the words SAME, DIFFERENT, BEFORE, and AFTER will be used in all capitals to denote the arbitrary contextual cue for which each particular function was established.

At the start of each probe, C stimuli (nonsense syllables) were presented vertically such that all four C stimuli $(\mathrm{C} 1, \mathrm{C} 2, \mathrm{C} 3$, or $\mathrm{C} 4)$ were presented in a random order. In between each pair of $C$ stimuli, arbitrary contextual cues for Before or After relational responding were presented (e.g., reading upwards: C1 BEFORE C2 BEFORE C3 BEFORE C4). There were 24 possible combinations of the contextual cues for Before relational responding and the four $\mathrm{C}$ stimuli presented (e.g., C1 BEFORE C2 BEFORE C3 BEFORE C4; C4 BEFORE C3 BEFORE C2 BEFORE $\mathrm{C} 1$; etc.). An additional 24 combinations employed contextual cues for After relational responding (e.g., C1 AFTER C2 AFTER C3 AFTER C4; 
C4 AFTER C3 AFTER C2 AFTER C1; etc.). For each test block (see below), 12 combinations from the possible 48 were sampled randomly.

One second after the presentation of the $\mathrm{C}$ stimuli and the BEFORE or AFTER cues in a particular order at the middle bottom of the screen, A, B, and C stimuli and Same or Different contextual cues were presented in a particular order in the top third of the screen. At the right-hand side of the top third of the screen, each $C$ stimulus was presented beneath a B stimulus and above these, a contextual cue for Same or Different relational responding was presented (e.g., reading upwards: C1 B1 SAME or C1 B1 DIFFERENT). On the left-hand side, in a similar position, each $B$ stimulus was presented beneath an A stimulus (a colored square) and above these a contextual cue for Same relational responding was presented (e.g., reading upwards: B1 A1 SAME). The B and C stimuli, and

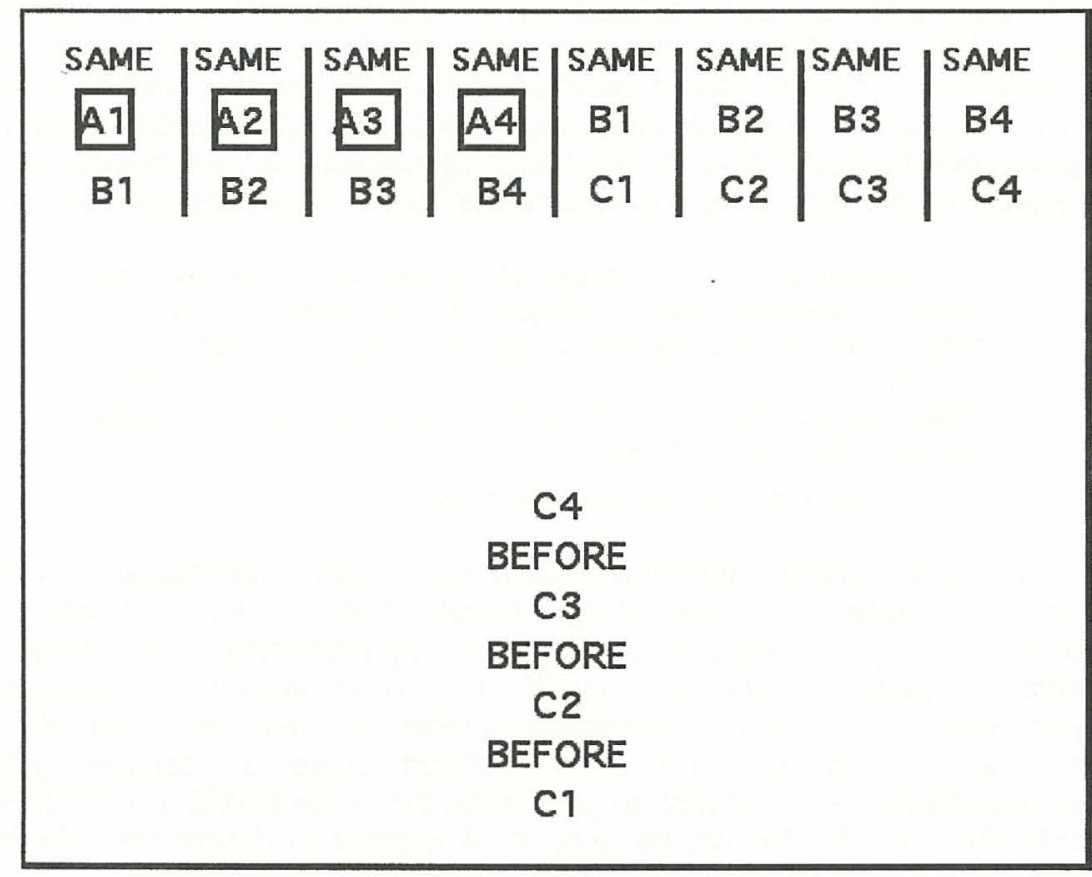

\section{Key: A1 Green Square A3 Yellow Square \\ A2 Red Square A4 Blue Square}

Figure 3. Diagrammatic representation of a test probe from the Test for Instructional Control. Four computer keys were designated response keys and were colored green, red, yellow, and blue. Sequences of responses were predicted based on the $C$ stimuli that were the SAME as the A stimuli according to the top of the screen (e.g., A1, green, is the same as B1, which is the same as C1) and the order of C stimuli and the presence of BEFORE or AFTER cues (e.g., C1 is before $\mathrm{C} 2$, which is before $\mathrm{C} 3$, and so on). The correct response to the above probe was Green - Red - Yellow - Blue. No reinforcement was provided during the test. 
the $A$ and $B$ stimuli were always presented in the same pairs (i.e., B1 was always presented with $C 1, A 1$ was always presented with $B 1, B 2$ with $C 2$, $A 2$ with $B 2$, and so on). Each of the eight pairs of stimuli (A1 to A4 with $B 1$ to $B 4$, and $B 1$ to $B 4$ with $C 1$ to $C 4$ ) was presented at random in one of the eight positions at the top of the screen for each probe. In the presence of this complex presentation of stimuli and contextual cues, subjects pressed as many colored response keys as they wished in whatever order they chose and then pressed the [RETURN] key. All stimuli remained on the screen until the [RETURN] key was pressed.

For each test probe, a particular four-key sequence constituted a correct response. For example, given the stimuli C1 BEFORE C2 BEFORE C3 BEFORE C4 (reading upwards) at the bottom of the screen, and the stimuli C1 B1 SAME / C2 B2 SAME / C3 B3 SAME / C4 B4 SAME, and B1 A1 (green) SAME / B2 A2 (red) SAME / B3 A3 (yellow) SAME / B4 A4 (blue) SAME at the top of the screen, it was expected that subjects would emit the following four-key response: Green - Red Yellow - Blue, followed by the [RETURN] key. In the presence of the DIFFERENT contextual cues, however, no specific response was prescribed by the relational network presented. Consider the following as an example: Given the stimuli C1 BEFORE C2 BEFORE C3 BEFORE C4 (reading upwards), and the stimuli C1 B1 DIFFERENT / C2 B2 DIFFERENT / C3 B3 DIFFERENT / C4 B4 DIFFERENT, and B1 A1 (green) SAME / B2 A2 (red) SAME / B3 A3 (yellow) SAME / B4 C4 (blue) SAME, the response 'specified' is: Not Green - Not Red - Not Yellow not Blue. In this case, any response other than Green - Red - Yellow Blue, followed by the [RETURN] key was considered correct.

Each exposure to the Test for Instructional Control consisted of three blocks of 12 test probes presented consecutively; Same Sequential probes, Same Nonsequential probes, and Different Nonsequential probes.

Same Sequential probes: For the first block of 12 probes, the $\mathrm{C}$ stimuli and Before or After contextual cues at the bottom of the screen (e.g., C1 BEFORE C2 BEFORE C3 BEFORE C4) were presented in a temporal sequence from bottom to top. This procedure was employed in order to encourage subjects to read from bottom to top. At the top of the screen, only SAME contextual cues were presented with the pairs of $A$ and $B$ stimuli and pairs of $B$ and $C$ stimuli.

Same Non-sequential probes: The second block of 12 probes also included only SAME contextual cues, but $\mathrm{C}$ stimuli and Before or After contextual cues appeared simultaneously at the bottom of the screen. The first 24 probes included only SAME contextual cues for two reasons. First, it was thought that these probes provided a closer analog to instructional control in the natural environment (e.g., "Open the Not-door" would be quite an unusual instruction). Second, we wished to avoid the possibility that the introduction of DIFFERENT cues might interfere with the demonstration of the derived performance in the presence of SAME.

Different Nonsequential probes: For the final 12 probes, C stimuli and Before or After contextual cues appeared simultaneously at the bottom of 
the screen, but DIFFERENT contextual cues were presented at the top of the screen with the pairs of $B$ and $C$ stimuli.

The mastery criterion for the Test for Instructional Control was a minimum of 10/12 correct responses on each of the three blocks of test probes. If subjects failed to demonstrate the required performance, they were exposed to either Before and After, or Same and Different pretraining and testing, based on their performance on the test (e.g., if a subject's performance suggested that Before and After cues failed to control responding, subjects were exposed to a test for Before and After relational responding). Subjects were excused from the experiment if they failed to demonstrate the required performance after four exposures to the Test for Instructional Control, or if they requested to leave the experiment at any time.

\section{Results and Discussion}

Table 1 shows the number of trials required by each subject to reach criterion in pretraining and testing for Before and After relational responding, Same and Different relational responding, and the Test for Instructional Control.

As an example, after exposure to 64 trials of pretraining for Before and After relations, Subject 1 demonstrated the performance required by the mastery criterion (14/16 on the last block of 16 trials). At this point,

\section{Table 1}

Number of Correct Responses in Each Phase of Pretraining, Testing, and Test for Instructional Control in Experiment 1

\begin{tabular}{|c|c|c|c|c|c|}
\hline & $\begin{array}{l}\text { Before/After } \\
\text { Pretraining }\end{array}$ & $\begin{array}{c}\text { Before/After } \\
\text { Test }\end{array}$ & $\begin{array}{c}\text { Same/ } \\
\text { Different } \\
\text { Pretraining }\end{array}$ & $\begin{array}{c}\text { Same/ } \\
\text { Different } \\
\text { Test }\end{array}$ & $\begin{array}{c}\text { Test for } \\
\text { Instructional } \\
\text { Control }\end{array}$ \\
\hline$\overline{S 1}$ & 64 & $32 / 32^{*}$ & 16 & $\begin{array}{l}16 / 16^{*} \\
16 / 16^{*}\end{array}$ & $\begin{array}{r}21 / 24 \mathrm{~S} \\
0 / 12 \mathrm{D} \\
23 / 24 \mathrm{~S}^{*} \\
12 / 12 \mathrm{D}^{*}\end{array}$ \\
\hline S2 & 64 & $\begin{array}{l}32 / 32^{*} \\
32 / 32^{*}\end{array}$ & 16 & $16 / 16$ & $\begin{array}{r}0 / 24 \mathrm{~S} \\
0 / 12 \mathrm{D} \\
20 / 24 \mathrm{~S}^{*} \\
12 / 12 \mathrm{D}^{*}\end{array}$ \\
\hline S3 & 32 & $\begin{array}{l}30 / 32^{*} \\
30 / 32^{*}\end{array}$ & 16 & $\begin{array}{l}15 / 16^{*} \\
16 / 16^{*} \\
15 / 16^{*}\end{array}$ & $\begin{array}{c}1 / 24 \mathrm{~S} \\
0 / 12 \mathrm{D} \\
19 / 24 \mathrm{~S} \\
1 / 12 \mathrm{D} \\
24 / 24 \mathrm{~S}^{*} \\
2 / 12 \mathrm{D} \\
23 / 24 \mathrm{~S}^{*} \\
0 / 12 \mathrm{D}\end{array}$ \\
\hline
\end{tabular}

Note. Asterisk denotes responding that satisfies the mastery criterion on that phase. In the Test for Instructional Control, the letters S and D denote test probes including Same and Different relational cues respectively. 
Subject 1 was exposed to a test for Before and After relations that incorporated novel stimuli without reinforcement and achieved the mastery criterion on her first exposure (32/32 correct). This subject then demonstrated the required performance after 16 trials of pretraining for Same and Different and passed the test for Same and Different relations on her first exposure. She was then exposed to the Test for Instructional Control and she responded correctly to 21 of the 24 probes in which Same contextual cues were presented, but responded correctly to none of the 12 trials in which Different contextual cues were introduced. On the basis of this performance, Subject 1 was reexposed to a test for Same and Different relational responding and then reexposed to the Test for Instructional Control. On her second exposure, she responded correctly to 23 of the 24 probes that included Same contextual cues, and responded correctly to all 12 of the probes that included Different contextual cues. Rather than detail each subject's performance, salient overall characteristics of all 3 subjects' performances on pretraining and testing for Before, After, Same, and Different relational responding and the Test for Instructional Control are presented below.

Pretraining and testing for Before, After, Same, and Different relational responding

All 3 subjects achieved the mastery criterion in the pretraining for Before and After relational responding within 64 trials. All 3 then demonstrated the required performance on the test for Before and After relational responding with novel stimuli and without feedback (a minimum of 30/32 correct). Same and Different relational responding required even less training. All 3 subjects responded to criterion after just 16 trials and passed the test with novel stimuli and without feedback on their first exposure (a minimum of 15/16 correct).

\section{Test for Instructional Control}

Of the 3 subjects, 2 responded in accordance with at least 32 out of the 36 novel networks of Same, Different, Before, and After relations without reinforcement on their second exposure. On her first exposure, Subject 1 responded correctly to 21 of the 24 probes in which Same contextual cues were presented, but responded correctly to none of the 12 trials in which Different contextual cues were introduced. As explained previously, she was then reexposed to a test for Same and Different relational responding. On her second exposure to the Test for Instructional Control, she responded correctly to 23 of the 24 probes that included Same contextual cues, and responded correctly to all 12 of the probes that included Different contextual cues.

On his first exposure, Subject 2 responded correctly to none of the 24 probes that included Same contextual cues and none of the 12 probes that included Different probes. A closer look at the data revealed that Subject 2 was responding in a reverse pattern to that expected. That is, Subject 2 responded to Before as After and After as Before. When the contextual cues for Different were introduced, Subject 2 repeatedly 
emitted the only incorrect response available on each trial (e.g., when the relational network specified Not Blue - Not Red - Not Yellow - Not Green, the subject pressed Blue - Red - Yellow - Green). Subject 2 was then exposed to a test for Before and After relational responding and passed on his first exposure (32/32). He was then reexposed to the Test for Instructional Control and responded correctly to 20 of the 24 probes that included Same contextual cues and all 12 of the probes that included Different contextual cues.

Subject 3 was exposed to the Test for Instructional Control and responded correctly to 1 of the 24 probes that included Same contextual cues and none of the 12 probes that included Different contextual cues. As with Subject 2, Before and After cues were controlling responding in the opposite direction to that expected, but Same and Different cues were also not controlling responding as expected. As a result, Subject 3 was exposed to both a test for Before and After responding (passed: 30/32 correct), and a test for Same and Different responding (passed: 16/16 correct). On his second exposure to the Test for Instructional Control, Subject 3 responded correctly on 19 of the 24 probes that included Same contextual cues but only responded correctly to 1 of the 12 probes that included Different contextual cues. Subject 3 was then exposed for a third time to a test of Same and Different relational responding (passed: 15/16 correct). On his third exposure to the Test for Instructional Control, Subject 3 responded correctly on 24 of the 24 probes that included Same contextual cues but only responded correctly to 2 of the 12 probes that included Different contextual cues. Subject 3 was then instructed to attend to the Same and Different contextual cues and reexposed to the Test for Instructional Control. On his fourth exposure to the Test for Instructional Control, Subject 3 responded correctly on 23 of the 24 probes that included Same contextual cues but responded correctly to none of the 12 probes that included Different contextual cues. At this point, Subject 3's participation was terminated.

\section{Experiment 2}

In Experiment 1,2 of the 3 subjects demonstrated the expected performances on their second exposures to the Test for Instructional Control. These performances required control by the contextual cues for Before and After relational responding and Same and Different relational responding. One subject demonstrated control by Before and After contextual cues but not control by Same and Different. Experiment 2 incorporated two significant modifications to address empirical and conceptual issues raised by these findings. First, in Experiment 1, the contextual cues for Different did not reliably control responding in the Test for Instructional Control for Subject 3. It was suggested that this might have been caused by the introduction of Different cues after subjects had previously completed 24 test probes with Same contextual cues. Research on instruction following has previously demonstrated that such 
responding may become 'rigid' or insensitive once established (e.g., Wulfert et al., 1994). One modification to Experiment 2, therefore, was that Different cues were introduced after the fourth test probe in the Test for Instructional Control.

A second modification concerned the generative nature of instructional control. For instance, a recent study by Dermer and Rodgers (1997) examined responding to numerous novel instructions. Specifically, the instructions employed consisted of one- to five-number digits between 0 and 99999 presented in word form (e.g., ONE-THREE-FOUR-TWOEIGHT) and subjects responded by pressing the prescribed number sequences using the number keys on a computer keyboard (e.g., 1-3-42-8). Dermer and Rodgers explained these performances in terms of control novel combinations of familiar discriminative stimuli. That is, it was suggested that subjects had a preexperimental history of reinforcement for pressing the 1 key in the presence of the stimulus ONE, for pressing the 2 key in the presence of the TWO stimulus and so on. Thus, by providing novel combinations of these previously trained stimuli, control by novel instructions was observed. That is, because the instructions were novel combinations of stimuli, the control observed could not be attributed to a history of reinforcement with respect to a particular instruction (i.e., instructions were rarely if ever repeated).

Although there have been theoretical objections to Dermer and Rodgers' position (e.g., Barnes-Holmes, Barnes-Holmes, \& Cullinan, 2000; Schlinger, 1993), it is incumbent upon any alternative account of control by novel instructions to demonstrate similar levels of generativity in a controlled laboratory setting. Towards this end, in Experiment 2, after successfully completing the initial Test for Instructional Control, subjects were exposed to a Test for Generalization of 24 further test probes each employing stimuli from a novel stimulus set. In this way, it was possible to examine whether the relational responding observed in the presence of one stimulus set would generalize to novel stimulus sets.

\section{Method}

\section{Subjects}

Eight undergraduates aged between 19 and 23 years, 4 male and 4 female, attending the National University of Ireland, Maynooth participated in Experiment 2.

\section{Apparatus}

In the Test for Generalization using multiple sets, eight sets of eight nonsense syllables, eight sets of eight arbitrary shapes, and eight sets of eight random pictures were employed. All other apparatus was the same as in Experiment 1.

\section{Procedure}

Pretraining and testing for Before, After, Same, and Different 

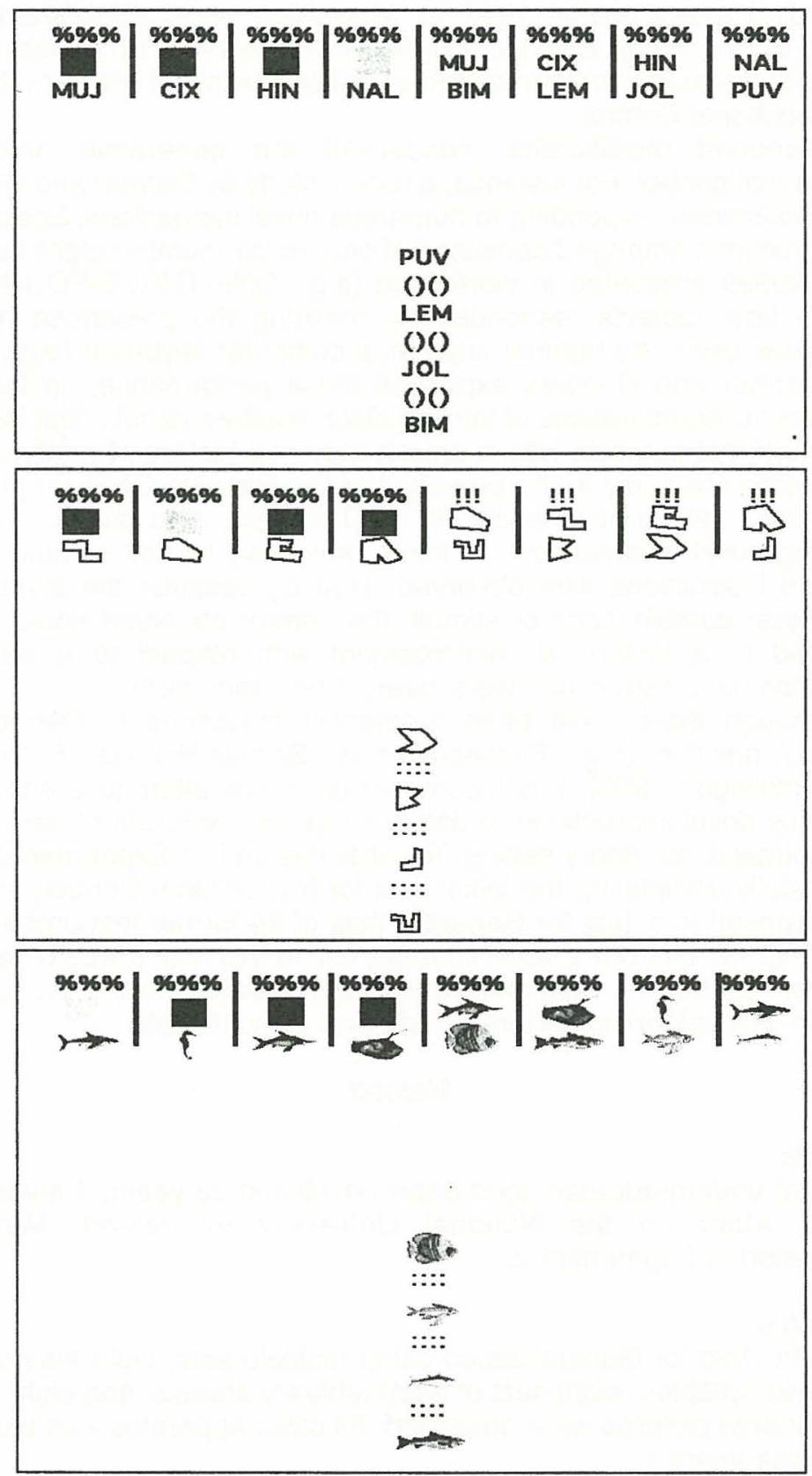

Figure 4. Three examples of test probes from the Test for Generalization. Following pretraining, the $\% \% \%, ! ! !,()(),::::$ symbols functioned as contextual cues for Same, Different, Before, and After relational responding. 
responding remained unchanged in Experiment 2. In the Test for Instructional Control, the test probes were reordered. Following the initial presentation of four Same Sequential probes, subjects were exposed to a combined block of 24 Nonsequential test probes, which was comprised of 12 Same Nonsequential and 12 Different Nonsequential test probes presented in no particular order.

\section{Test for Generalization}

When subjects reached criterion on the Test for Instructional Control in Experiment 2, they were exposed to a variation of this test that included 24 novel stimulus sets. No Sequential test probes were presented in this test phase. Otherwise, the method of presentation was identical to that in the Test for Instructional Control. The critical difference between the Test for Generalization and the Test for Instructional Control was that a different stimulus set was presented on each of 24 test probes. The first eight stimulus sets presented consisted of novel sets of nonsense syllables. These eight novel stimulus sets appeared in a quasi-random order such that all eight sets appeared within a block of eight test probes. The second eight stimulus sets consisted of nonsense shapes, and the final eight stimulus sets consisted of clip art pictures of particular themes acquired from the Appleworks software package (e.g., fish, dinosaurs, cars). These eight quasi-randomly presented stimulus sets constituted the final block of eight test probes. An example from each of the three blocks of eight test probes is presented in Figure 4.

\section{Results and Discussion}

Of the 8 subjects in Experiment 2, 5 demonstrated the expected performances in the Test for Instructional Control and the Test for Generalization, which employed multiple stimulus sets. The performance of subjects on each phase of the experiment is presented in Table 2. Subject 5, for example, demonstrated relational responding in accordance with Before and After relations after exposure to two blocks of 16 trials. She then responded to criterion on the test for Before and After relational responding with novel stimuli and without feedback (32/32). After 16 trials, she demonstrated responding in accordance with Same and Different relations and then responded to criterion on a test with novel stimuli and without feedback (16/16). She was then exposed to a Test for Instructional Control and reached criterion on her first exposure (26/28). Finally, she was exposed to a Test for Generalization, in which each probe included stimuli from 1 of 24 novel stimulus sets, and she demonstrated the expected performance on every probe (24/24). As in Experiment 1, salient overall characteristics of subjects' performances on pretraining for Before and After relational responding, the Test for Instructional Control and the Test for Generalization are presented in the following sections. 
Table 2

Number of Correct Responses in Each Phase of Pretraining,

Testing, and Test for Instructional Control in Experiment 2

\begin{tabular}{|c|c|c|c|c|c|c|}
\hline & $\begin{array}{c}\text { Before/ } \\
\text { After } \\
\text { Pretraining }\end{array}$ & $\begin{array}{c}\text { Before/ } \\
\text { After } \\
\text { Test }\end{array}$ & $\begin{array}{c}\text { Same/ } \\
\text { Different } \\
\text { Pretraining }\end{array}$ & $\begin{array}{c}\text { Same/ } \\
\text { Different } \\
\text { Test }\end{array}$ & $\begin{array}{c}\text { Test for } \\
\text { Instructional } \\
\text { Control }\end{array}$ & $\begin{array}{c}\text { Test for } \\
\text { Generalization }\end{array}$ \\
\hline S4 & 64 & $\begin{array}{l}32 / 32^{*} \\
32 / 32^{*}\end{array}$ & 16 & $\begin{array}{l}16 / 16^{*} \\
16 / 16^{*}\end{array}$ & $\begin{array}{l}19 / 28 \\
12 / 28 \\
22 / 28^{*}\end{array}$ & $22 / 24^{*}$ \\
\hline S5 & 32 & $32 / 32^{*}$ & 16 & $16 / 16^{*}$ & $26 / 28^{*}$ & $24 / 24^{*}$ \\
\hline S6 & 96 & $\begin{array}{l}32 / 32^{*} \\
32 / 32^{*}\end{array}$ & 16 & $\begin{array}{l}16 / 16^{*} \\
16 / 16^{*}\end{array}$ & $\begin{array}{l}0 / 28 \\
0 / 28 \\
2 / 28\end{array}$ & \\
\hline S7 & 80 & $32 / 32$ & 32 & $16 / 16$ & $26 / 28^{*}$ & $23 / 24^{*}$ \\
\hline S8 & 64 & $\begin{array}{l}32 / 32^{*} \\
32 / 32^{*}\end{array}$ & $\begin{array}{r}16 \\
8\end{array}$ & $\begin{array}{l}16 / 16^{*} \\
16 / 16^{*} \\
16 / 16^{*}\end{array}$ & $\begin{array}{l}17 / 28 \\
15 / 28 \\
13 / 28 \\
11 / 28 \\
16 / 28\end{array}$ & \\
\hline S9 & $\begin{array}{c}160 \\
32\end{array}$ & $\overline{32 / 32^{*}}$ & 16 & $\begin{array}{l}16 / 16^{*} \\
16 / 16^{*}\end{array}$ & $\begin{array}{l}13 / 28 \\
27 / 28^{*}\end{array}$ & $23 / 24^{*}$ \\
\hline $\mathrm{S} 10$ & $\begin{array}{l}96 \\
32\end{array}$ & $\begin{array}{l}- \\
32 / 32^{*} \\
32 / 32^{*} \\
32 / 32^{*}\end{array}$ & 16 & $\begin{array}{l}16 / 16^{*} \\
16 / 16^{*} \\
16 / 16^{*}\end{array}$ & $\begin{array}{l}18 / 28 \\
15 / 28 \\
26 / 28^{*} \\
27 / 28^{*}\end{array}$ & $23 / 24^{*}$ \\
\hline S11 & 96 & $32 / 32^{*}$ & 16 & $\begin{array}{l}16 / 16^{*} \\
16 / 16^{*}\end{array}$ & $18 / 28^{* *}$ & $\begin{array}{l}17 / 24 \\
13 / 24\end{array}$ \\
\hline
\end{tabular}

Note. A single asterisk denotes responding that satisfies the mastery criterion on that phase. Subject 11 was exposed to the Test for Generalization without demonstrating the required performance in the Test for Instructional Control.

\section{Pretraining for Before and After Relational Responding}

Subject 5 was the only subject to demonstrate responding in accordance with Before and After relations after two blocks of 16 pretraining trials. Subjects 4 and 8 required four blocks of pretraining trials, Subject 7 required five blocks, and Subjects 6 and 11 required six blocks. All 5 subjects demonstrated the required performance on the test for Before and After relational responding with novel stimuli and without feedback.

Subject 9 (10 exposures) and Subject 10 (6 exposures) failed to demonstrate responding in accordance with Before and After relations (Subject 10 requested a short recess). At this point, both subjects were exposed to Same and Different relational pretraining, which they both successfully completed, before being reexposed to pretraining for Before 
and After relational responding. Both subjects reached the mastery criterion after two blocks of 16 trials and successfully passed the test with novel stimuli and without feedback.

It is not clear why the subjects in Experiment 2 required more training than those in Experiment 1 before achieving the mastery criterion. There were no differences in the timing or design of the stimuli. Indeed, it was a computer program identical to that used in Experiment 1.

\section{Test for Instructional Control}

Successful performance in this test required subjects' relational performances to be controlled by Same, Different, Before, and After contextual cues. Five subjects demonstrated the required performance on the Test for Instructional Control. Subjects 5 and 7 achieved the mastery criterion on their first exposure, Subject 9 on his second exposure, and Subjects 4 and 10 on their third exposures. Subjects 6 and 8 failed to demonstrate the required performance after three and six exposures respectively. Finally, Subject 10 was reexposed to the Test for Instructional Control to test whether reexposing subjects to the Test for Instructional Control may have served as implicit feedback (e.g., a 'didn't proceed therefore change' strategy). This subject's performance did not change on reexposure.

\section{Test for Generalization}

All 5 subjects who demonstrated control in accordance with Same, Different, Before, and After relations in the Test for Instructional Control (Subjects 4, 5, 7, 9, and 10) also demonstrated the expected performances on the Test for Generalization on their first exposure. In order to test whether these performances were simply caused by some aspect of the Test for Generalization itself, Subject 11 was exposed to the Test for Generalization without first achieving the mastery criterion in the Test for Instructional Control. This subject failed to demonstrate the required performance on the Test for Generalization after two exposures.

\section{General Discussion}

Across two experiments, 8 of 12 subjects demonstrated responding in accordance with networks of derived Same, Different, Before, and After relations. The performances of these subjects constitute an empirical analog of the instruction suggested by S. C. Hayes and Hayes (1989) "When the bell rings, take the cake from the oven." Furthermore, the control by novel instructions observed in the current study was directly attributable to the relational pretraining to which subjects had been exposed. In Experiment 2, 5 subjects responded correctly in the Test for Instructional Control and all 6 demonstrated control by relational cues for Same, Different, Before, and After in the presence of 24 novel stimulus sets. One subject who had not passed the Test for Instructional Control was exposed to the test including 24 novel stimulus sets and failed to 
demonstrate control by the relational cues. These performances underline the generativity of the relational control observed and lend convincing weight to the argument that these performances may provide a useful behavioral analog of instructional control and language more generally (see S. C. Hayes \& Hayes, 1989).

In the current study, novel instructions composed of networks of derived stimulus relations controlled four-key sequence responses for 8 of 12 subjects across two experiments. These performances supplement previous studies on novel instructions in a number of ways. First, L. J. Hayes, Thompson, and Hayes (1991) demonstrated instructed performances in the presence of previously neutral stimuli, but neither they nor Dermer and Rodgers (1997) demonstrated control over the sequence of responses. It was not possible, therefore, to demonstrate the reversibility of instructed sequences based on the procedures described in both of these previous studies. In contrast, in the current study, the sequence of responses was controlled by relational cues for Before and After established in pretraining, and reversibility of response sequences was observed. An additional aspect of control by novel instructions was thus demonstrated in the current study. Furthermore, the performances observed in the current study not only involved transfer of function in accordance with Same relations but also the transformation of functions in accordance with Before and After relations (see Barnes-Holmes et al., 2001, for a detailed discussion).

Second, the demonstration of control by the relational cues for Same, Different, Before, and After in the presence of 24 novel stimulus sets in Experiment 2 rivals Dermer and Rodgers' (1997) number of possible permutations. However, Dermer and Rodgers explained their findings in terms of a pre-experimental history of differential reinforcement for making certain responses (e.g., pressing the 1 key) in the presence of certain word stimuli (e.g., ONE). Conversely, the control observed in the current study was based on an experimental history of reinforcement. This represents an improvement because the histories that gave rise to the performances could in principle be manipulated in order to isolate controlling variables. Furthermore, in the Dermer and Rodgers study, sequences of stimuli were rarely repeated, but in the final stage of the current study, not even the stimuli within the sequences were repeated. That is, on each probe, novel stimuli were related to novel stimuli in accordance with relational cues under experimental control.

A number of studies have previously examined untrained sequence responding (e.g., Cullinan, Barnes, Hampson, \& Lyddy, 1994; Green, Stromer, \& Mackay, 1993; Lazar, 1977; Lazar \& Kotlarchyk, 1986; Lyddy, Hampson, \& Barnes-Holmes, \& 2001; Wulfert \& Hayes, 1988). Typically, in such studies, subjects are first trained on a number of conditional discriminations to establish two classes of stimuli (e.g., A1, B1, and C1 in one class, and $\mathrm{A} 2, \mathrm{~B} 2$, and $\mathrm{C} 2$ in another), and then they are trained to respond in a particular sequence to two stimuli, one from each class (e.g., A1 then A2). Subjects are then tested for a transfer of sequence function 
to the other class members (i.e., given $\mathrm{B} 1$ and $\mathrm{B} 2$, do subjects respond to B1 and then B2?). Although such studies have demonstrated convincing emergent sequences (e.g., in the Wulfert \& Hayes study, approximately 120 novel sequences emerged from only eight trained sequences), the performances demonstrated required explicit training of sequence responding. In the current study, control by contextual cues for Before and After was established in a pretraining preparation. In this way, the relational responding in accordance with Before and After were reinforced in the presence of arbitrary cues. This relational history then gave rise to appropriate control of sequence responding during the Test for Instructional Control.

One consideration that might be made with regard to the current study concerns the use of adult human subjects. The performances that were observed in the current study were likely based, to some extent, on the preexperimental histories of the subjects. Indeed, as college students were employed as subjects, we might conservatively estimate that they had highly versatile verbal repertoires. Thus, although the contextual cues for Same, Different, Before, and After demonstrated control over subjects' relational responses, it is highly unlikely that these procedures established these verbal repertoires in whole cloth. Future research might well employ subjects with verbal repertoires that are deficient in some particular respect and develop intervention programs to remediate these performances. In such circumstances, the procedures described herein may provide a starting point for such programs.

A related issue concerns the fact that 4 of the 11 subjects failed to respond in accordance with the relational networks presented during the Test for Instructional Control. As previously mentioned, however, the subjects were college students, and therefore it is highly unlikely that they were unable to follow simple verbal instructions. One might argue that the failure of these subjects undermines the credibility of the current model of instructional control. Although future research will need to target the subjects who fail with systematic intervention procedures, a number of factors seem particularly relevant in explaining the current failures. First, the 'instructions' presented during these tests were quite distinct formally from any instructions subjects might have seen previously (e.g., no natural language is read from bottom to top). Second, subjects received no feedback on their many responses to the test probes whereas natural language instructions are often followed by contingent consequences. In the current study, however, subjects were required to respond in accordance with numerous novel instructions without any feedback. Indeed, subjects were unpaid volunteers. Anecdotally, in the Maynooth laboratory, we have previously found that, on complex relational tasks, the provision of contingent monetary rewards during baseline training increases dramatically the number of subjects who demonstrate expected test performances.

The foregoing factors may also help to explain why most subjects who passed the Test for Instructional Control required at least two exposures to the training and testing phases. Indeed, only 2 subjects demonstrated the 
expected performance during their first exposure to the instructional test. Nevertheless, such a finding is not unusual in studies of stimulus equivalence or other derived relational performances. On the contrary, subjects are frequently recycled between training and testing before derived performances emerge (e.g., Barnes \& Keenan, 1993). In fact, given the complexity of the relational performances required in the current study, the relatively low number of reexposures required by the subjects who passed might well stand as testimony to the power of the current model.

The current experiments represent the first attempts to model instructional control as responding in accordance with networks of derived stimulus relations. Now that this model has been successfully tested in the behavioral laboratory, future studies could reexamine effects demonstrated in studies of instructional control that have employed natural language stimuli. Previous research has demonstrated the operant properties of instruction following (e.g., deGrandpre \& Buskist, 1991), and thus future studies could examine whether the derived instructional performances demonstrated in the current experiments will also possess such properties (cf. Healy, Barnes, \& Smeets, 1998; Healy, Barnes-Holmes, \& Smeets, 2000). For example, ongoing work in the Maynooth laboratory is currently analyzing the effect of providing differential feedback on the types of derived instructional responding reported in the current study.

On a theoretical note, the performances demonstrated in the current study provide a necessary empirical counter argument to Chomsky's (1959) assertion that behavioral approaches could not account for control by novel stimuli or for the generative nature of language. Although there have been comprehensive theoretical replies to Chomsky's arguments (e.g., MacCorquodale, 1969), in the empirical arena, there have been precious few behavioral attempts to demonstrate control by novel verbal stimuli and even fewer to establish generative verbal control. Indeed, because cognitive psychologists have a very different conceptual outlook, theoretical rebuttals of Chomsky's position are unlikely to convince such researchers. However, the empirical demonstration of complex language-like performances such as those observed in the current study are arguably more likely to interest psychologists from all traditions. The current research, therefore, constitutes a critical empirical example of the viability of behavioral approaches in the study of complex language and cognitive phenomena.

\section{References}

AYLLON T., \& AZRIN, N. H. (1964). Reinforcement and instructions with mental patients. Journal of The Experimental Analysis of Behavior, 6, 327-331.

BARNES, D., \& KEENAN, M. (1993). A transfer of functions through derived arbitrary and non-arbitrary stimulus relations. Journal of The Experimental Analysis of Behavior, 59, 61-81. 
BARNES-HOLMES, D., BARNES-HOLMES, Y., \& CULLINAN, V. (2000). Relational frame theory and Skinner's Verbal Behavior. A possible synthesis. The Behavior Analyst, 23, 69-84

BARNES-HOLMES, D., HAYES, S. C., DYMOND, S., \& O'HORA, D. (2001). Multiple stimulus relations and the transformation of stimulus functions. In S. C. Hayes, D. Barnes-Holmes, \& B. T. Roche (Eds.), Relational frame theory: A post-Skinnerian account of human language and cognition. New York: Plenum.

CHOMSKY, N. (1959). A review of B. F. Skinner's Verbal Behavior. Language, 35, 26-58.

COHEN, J. D., MACWHINNEY, B., FLATT, M., \& PROVOST, J. (1993). PsyScope: A new graphic interactive environment for designing psychology experiments. Behavioral Research Methods, Instruments and Computers, 25(2), 257-271.

CULLINAN, V., BARNES, D., HAMPSON, P. J., \& LYDDY, F. (1994). A transfer of explicitly and nonexplicitly trained sequence responses through equivalence relations: An experimental demonstration and connectionist model. The Psychological Record, 44, 559-585.

CULLINAN, V., BARNES, D., \& SMEETS, P. M. (1998). A precursor to the relational evaluation procedures: Analyzing stimulus equivalence. The Psychological Record, 48, 121-145.

CULLINAN, V., BARNES-HOLMES, D., \& SMEETS, P. M. (2000). A precursor to the relational evaluation procedure: Analyzing stimulus equivalence II. The Psychological Record, 50, 467-492.

CULLINAN, V., BARNES-HOLMES, D., \& SMEETS, P. M. (2001). Precursor to the relational evaluation procedure: The search for the contextual cues that control equivalence responding. Journal of the Experimental Analysis of Behavior, 76, 339-349.

DEGRANDPRE, R. J., \& BUSKIST, W. F. (1991). Effects of accuracy of instructions on human behavior: Correspondence with reinforcement contingencies matters. The Psychological Record, 41, 371-384.

DERMER, M. L., \& RODGERS, J. G. (1997). Schedule control over following instructions comprised of novel combinations of verbal stimuli. The Psychological Record, 47, 243-260.

DYMOND, S., \& BARNES, D. (1995). A transformation of self-discrimination functions in accordance with the derived stimulus relations of Sameness, More than, and Less than. Journal of the Experimental Analysis of Behavior, 64, 163-184.

GREEN, G., STROMER, R., \& MACKAY, H. A. (1993). Relational learning in stimulus sequences. The Psychological Record, 43, 585-615.

HAYES, L. J., THOMPSON, S., \& HAYES, S. C. (1989). Stimulus equivalence and rule following. Journal of the Experimental Analysis of Behavior, 52, 275-291.

HAYES, S. C., \& BARNES, D. (1997). Analyzing derived stimulus relations takes more than the concept of stimulus class. Journal of The Experimental Analysis of Behavior, 68, 235-244.

HAYES, S. C., \& HAYES, L. J. (1989). The verbal action of the listener as a basis for rule governance. In S. C. Hayes (Ed.), Rule governed behavior: Cognition, contingencies, and instructional control (pp. 153-190). New York: Plenum Press.

HAYES, S. C., ZETTLE, R. D., \& ROSENFARB, I. (1989). Rule following. In S. C. Hayes (Ed.), Rule governed behavior: Cognition, contingencies, and instructional control (pp. 191-220). New York: Plenum. 
HEALY, O., BARNES, D., \& SMEETS, P. M. (1998). Derived relational responding as an operant: The effects of between-session feedback. The Psychological Record, 48, 511-536.

HEALY, O., BARNES-HOLMES, D., \& SMEETS, P. M. (2000). Derived relational responding as generalized operant behavior. Journal of the Experimental Analysis of Behavior, 74, 207-227.

KAUFMAN, A., BARON, A., \& KOPP, R. E. (1966). Some effects of instructions on human operant behavior. Psychonomic Monograph Supplements, 1, 243250.

LAZAR, R. (1977). Extending sequence-class membership with matching to sample. Journal of the Experimental Analysis of Behavior, 27, 381-392.

LAZAR, R. M., \& KOTLARCHYK, B. J. (1986). Second order control of sequenceclass equivalences in children. Behavioral Processes, 13, 205-215.

LYDDY, F., BARNES-HOLMES, D., \& HAMPSON, P. (2001). Transfer of sequence function via equivalence in connectionist network. The Psychological Record, 51, 409-428.

MACCORQUODALE, K. (1969). B. F. Skinner's Verbal Behavior. A retrospective appreciation. Journal of The Experimental Analysis of Behavior, 12, 831-841.

O'HORA, D., \& BARNES-HOLMES, D. (2001). The referential nature of rules and instructions: A response to "Instructions, rules, and abstraction: A misconstrued relation" by Emilio Ribes-Inesta. Behavior and Philosophy, 29, 21-25.

O'HORA, D., BARNES-HOLMES, D., \& ROCHE, B. (2001). Developing a procedure to model the establishment of rule governance. Experimental Analysis of Human Behavior Bulletin, 19, 14-16.

O'HORA, D., ROCHE, B., BARNES-HOLMES, D., \& SMEETS, P. M. (2002). Response latencies to multiple derived stimulus relations: Testing two predictions of Relational Frame Theory. The Psychological Record, 52, 51-75.

OKOUCHI, H. (1999). Instructions as discriminative stimuli. Journal of The Experimental Analysis of Behavior, 72, 205-214.

ROCHE, B., \& BARNES, D. (1996). Arbitrarily applicable relational responding and sexual categorization: A critical test of the derived difference relation. The Psychological Record, 46, 489-507.

ROCHE, B., \& BARNES, D. (1997). A transformation of respondently conditioned stimulus function in accordance with arbitrarily applicable relations. Journal of the Experimental Analysis of Behavior, 67, 275-300.

SCHLINGER, H. D. (1993). Separating discriminative and function-altering effects of verbal stimuli. The Behavior Analyst, 16, 9-23.

SKINNER, B. F. (1969). Contingencies of reinforcement: A theoretical analysis. New York: Appleton-Century-Crofts.

STEELE, D., \& HAYES, S. C. (1991). Stimulus equivalence and arbitrarily applicable relational responding. Journal of the Experimental Analysis of Behavior, 56, 519-555.

WULFERT, E., \& HAYES, S. C. (1988). The transfer of conditional sequencing through conditional equivalence classes. Journal of the Experimental Analysis of Behavior, 50, 125-144. 